\title{
Attachments of infant guinea pigs
}

W. SLUCKIN and CLARE FULLERTON, University of Leicester, Leicester, LE1, 7RH, England

Infant guinea pigs were "exposure-trained" with either a rotating striped cube or a tennis ball. When they were tested later for choice between the cube and the ball, the animals were found to spend more time near the object with which they had been "trained." A total training period of 20 min proved to be just as effective as one of $4 \mathrm{~h}$. Control animals, exposed to an empty training pen, preferred the cube.

It is well known that the infant guinea pig, isolated from its mother, is attracted to suitable moving objects (Shipley, 1963). It has also been shown that young guinea pigs can become attached to such objects, preferring familiar to strange ones (Sluckin, 1968). No attempt, however, has been made so far to investigate attachment behavior of this kind in relation to the duration of "training" or to the degree of initial attractiveness of the stimulus figure. The present experiment sets out to do this, using two types of objects and two different exposure periods.

\section{METHOD}

The newborn animals were left with the mother until 4-6 days old. Each was then removed to an individual rearing box, $8 \times 8 \times 12$ in. deep, with food and water available ad lib. Subsequently, each guinea pig was "trained" during the next two mornings, and it was then tested on the second afternoon, that is, when 6-8 days of age. The training pens were all $2 \mathrm{ft} \times 1 \mathrm{ft} \times 11$ in. deep, painted inside matte black, either empty or containing a striped black-and-white cube measuring $2 \frac{1}{4}$ in. or a standard tennis ball, either object being mounted near one end of the pen and moving in a circular motion (radius approximately $1 \mathrm{in}$.) at the rate of $10 \mathrm{rpm}$.

The 59 Ss were assigned in rotation to five groups for training as follows: (1) two 10 min training sessions with the cube on two consecutive mornings, (2) likewise with the ball, (3) two 2-h training sessions with the cube, (4) likewise with the ball, (5) likewise in the empty pen; in no case was food or water provided. All animals were subsequently tested individually, and the testing procedure was the same for all the groups. The testing pen was of the same size as the training ones, but had the striped cube moving at one end and the tennis ball moving at the other. Its floor was divided into three sections; the central one approximately 5 in. wide, was rigidly
Table 1

Mean Times, to the Nearest Second, Spent with $B$ all and Cube by the 5 Groups; Standard Deviations in Brackets

\begin{tabular}{lcc}
\hline Training & Ball & Cube \\
\hline $\begin{array}{c}20 \text { min Ball } \\
\text { N } 12\end{array}$ & $787[360]$ & $270[252]$ \\
20 min Cube & $146[181]$ & $925[272]$ \\
$\quad$ N 12 \\
$\begin{array}{l}4 \text { h Ball } \\
\text { N } 12\end{array}$ & $681[393]$ & $304[296]$ \\
4 h Cube & $150[223]$ & $992[218]$ \\
N 11 & & \\
4 h Control & $210[264]$ & $687[386]$ \\
N 12 &
\end{tabular}

mounted, whereas the two end ones could be slightly depressed by the weight of the animal, thereby closing a switch and thus starting an electronic decade timer. Each animal was first placed in the central section facing the back wall of the pen (i.e., with the cube on the right); at the end of $10 \mathrm{~min}$, it was removed from the pen and put into its rearing box for $5 \mathrm{~min}$, and then retumed to the testing pen, now facing the front wall (i.e., with the ball on its right), and was left there for another $10 \mathrm{~min}$. The total time spent by each animal with the cube and with the tennis ball during the 20 min was noted. RESULTS

The results are summarized in Table 1. The differences between "ball scores" and "cube scores" in each of the five groups were compared by the Wilcoxon matched-pairs signed-ranks test, and these are set out in Table 2. It will be seen that object-trained animals spent more time with the object they had previously experienced; the untrained animals showed a decided preference for the cube. The ball scores of groups of animals with the same training object, but with different training periods, were compared with one another-as were the cube scores-by means of Mann-Whitney $\mathrm{U}$ tests, and the differences in no case were found to be significant. It is clear, against the background of the 2-h control results, that the ball training has been highly effective; cube training, too, has had some effect: 4 -h control cube scores vs 4 h cube-training cube scores, $U=37, p<.05$ one-tailed, $p<.10$

Table 2

Wikcoxon Matched-Pairs Signed-Ranks Two-Tail Tests

\begin{tabular}{l|l|l|l}
\hline Training & \\
\hline 20 min Ball & $\mathrm{N}=12$ & $\mathrm{~T}^{-}=13$ & $\mathrm{p}<.05$ \\
$20 \mathrm{~min}$ Cube & $\mathrm{N}=12$ & $\mathrm{~T}^{+}=2$ & $\mathrm{p}<.01$ \\
$4 \mathrm{~h}$ Ball & $\mathrm{N}=12$ & $\mathrm{~T}^{-}=16$ & $\mathrm{p}>0.05$ \\
$4 \mathrm{~h}$ Cube & $\mathrm{N}=11$ & $\mathrm{~T}^{+}=3$ & $\mathrm{p}<.01$ \\
$4 \mathrm{~h}$ Control & $\mathrm{N}=12$ & $\mathrm{~T}^{+}=9$ & $\mathrm{p}<.01$ \\
\hline
\end{tabular}

two-tailed. It may be noted, however, that in view of the untrained animals' preference for the cube, there was relatively less scope for cube training to lead to improved cube scores.

\section{DISCUSSION}

Our results confirm earlier findings that infant guinea pigs develop preferences for figures to which they have been exposed (Sluckin, 1968). A very marked change of preference develops in animals exposed to objects that would be initially nonpreferred. This shift of preference towards relatively unattractive stimuli is comparable with the development of exposure-acquired attachments by young domestic chicks to initially attractive textures (Taylor et al, 1967) or colors (Taylor et al, 1969). An interesting finding of the present experiment is that a total of $20 \mathrm{~min}$ of training was as effective as $4 \mathrm{~h}$. It is a matter for further research to determine when diminishing returns begin to accrue from extra exposure.

The acquisition of attachments by young guinea pigs may be regarded as essentially a process of imprinting in a mammalian species (Sluckin, 1968). It seems likely that the development of attachments in infant guinea pigs follows a somewhat similar course to that of social attachments in lambs (Cairns, 1966a). It is, of course, possible to look upon such findings simply as evidence that "animals tend to remain in the presence of objects to which they have been continuously exposed [Cairns, 1966b]."It is tempting, however, to attempt an explanation of such a developmental process, and Cairns (1966b) does this in terms of a model in the tradition of associative-leaming theory. However, by describing the developments of attachments in guinea pigs and other mammals as imprinting, one need not be at all committed to any particular explanation of such learning, for it is well known that there is no generally agreed theoretical account of imprinting in birds (Sluckin, 1964; Bateson, 1966). It is felt that by not eschewing the term, imprinting, in the present context, some desirable emphasis is laid on the similarity between the growth of specific "self-reinforced" attachments in precocial mammals and that in precocial birds.

\section{REFERENCES}

BATESON, P. P. G. The characteristics and context of imprinting. Biological Review, 1966, 41, 177-220.

CAIRNS, R. B. Development, maintenance and extinction of social attachment beheviour in sheep. Joumal of Comparative \& Physiological Psycholozy, 1966a, 62, 298-306.

CAIRNS, R. B. Attachment behavior in mammals. Psychological Review, 1966b, 73, 409-426.

SHIPLEY, W. U. The demonstration in the domestic guine-pig of a process resembling classical imprinting. Animal Behaviour, 1963, $11,470-474$. 
SLUCKIN, W. Imprinting and early learning. London: Methuen, 1964.

SLUCKIN, W. Imprinting in guinea-pigs. Nature, $1968,220,1148$.

TAYLOR, A., SLUCKIN, W., HEWITT, R., \& GUITON, P. The formation of attachments by domestic chicks to two textures. Animal Behaviour, 1967, 15, 514-519.

TAYLOR, A., SLUCKIN, W., \& HEWITT, R.
Changing colour preferences in chicks. Animal Behaviour, 1969, 17, 3-8.

\section{NOTE}

1. We should like to acknowledge the help we have had from the following: Julia Berryman, Linda Biddles, J. A. Darley, Ann Taylor Davies, D. MacArthur, Valerie Metcalfe, and Elizabeth Tetlow.

\section{Pemoline and magnesium hydroxide (PMH): Performance enhancement after ECS}

\section{N. PLOTNIKOFF, Department of Pharmacology, Abbott Laboratories, North Chicago, Ill. 60064}

In a double-blind study, PMH was demonstrated to enhance performance during acquisition of a conditioned avoidance response in rats following electroconvulsive shock. This antagonism of antegrade amnesia by PMH is interpreted as further evidence of enhancement of consolidation of memory processes.

Earlier studies by Plotnikoff (1966b, 1968) indicated that pemoline and magnesium hydroxide (PMH) antagonized the retrograde amnesic effects of electroconvulsive shock in rats and rabbits. As a result of our animal studies, Small, Sharpley, \& Small (1968) initiated clinical trials and recently reported that $\mathrm{PMH}$ improved aspects of learning and memory in humans receiving electroconvulsive shock trcatment. The present study attempts to provide additional experimental data that PMH also antagonizes antegrade amnesia of the earlier-reported conditioned-avoidance response in rats.

The test chamber used for all conditioning studies was described previously (Plotnikoff, 1966a). Essentially, the apparatus consisted of a wooden test chamber with a grid flooring and an escape platform placed outside the chamber (left side). Rats were placed on the grid floor through a plastic door from the right side. An acquisition trial consisted of the following 30-sec sequence: the first $15 \mathrm{sec}$ inside the chamber without shock or buzzer, followed by $10 \mathrm{sec}$ with buzzer, and finally, $5 \mathrm{sec}$ with buzzer and shock. The intertrial interval was $8.12 \mathrm{~min}$.

Male Sprague-Dawley rats (Charles River Laboratories), weighing approximately 220-250 g, were used in these experiments. PMH, suspended in $0.3 \%$ tragacanth, was given orally. Thirty minutes after medication, electroshock was administered via corneal electrodes $(150 \mathrm{~mA}, 0.4 \mathrm{sec}$, Wahlquist apparatus), which produced maximal tonic-clonic convlusions. No significant alteration of maximal seizures was observed in PMH-treated animals. Fifteen minutes after electroshock, the animals' performance was measured in 10 acquisition trials in the jump-out test. All studies were conducted on a double-blind basis and represent the pooled sample of two studies.

The results, expressed as mean latencies of jump-out time from the test apparatus following electroshock, can be seen in Table 1. Rats pretreated with PMH at doses of 10 to $40 \mathrm{mg} / \mathrm{kg}$ had significantly shorter mean jump-out latencies compared to control animals. In addition, the trial number in which animals reached criteria of acquisition was significantly shorter for

Table 2

Mean Latencies of Jump Out Times of Rats After Electroconvulsive Shock

\begin{tabular}{ccccc}
$\begin{array}{c}\text { Trial } \\
\text { Number }\end{array}$ & $\begin{array}{c}\text { Controls } \\
(\mathbf{N}=40)\end{array}$ & $\begin{array}{c}\text { PMH 10 mg/kg } \\
(\mathbf{N}=20)\end{array}$ & $\begin{array}{c}\text { PMH 20 mg/kg } \\
(\mathbf{N}=20)\end{array}$ & $\begin{array}{c}\text { PMH 40 mg/kg } \\
(\mathbf{N}=20)\end{array}$ \\
\hline 1 & $30.0 \pm 0.0$ & $29.7 \pm 0.2$ & $29.9 \pm 0.1$ & $29.9 \pm 0.1$ \\
2 & $27.9 \pm 0.3$ & $26.9 \pm 0.7$ & $25.6 \pm 1.4$ & $25.3 \pm 1.3$ \\
3 & $22.6 \pm 1.3$ & $16.7 \pm 2.3$ & $17.4 \pm 2.2$ & $11.8 \pm 1.8^{*}$ \\
4 & $19.5 \pm 1.4$ & $17.3 \pm 2.4$ & $13.6 \pm 2.0^{*}$ & $9.3 \pm 1.7$ \\
5 & $19.4 \pm 1.3$ & $15.3 \pm 1.9$ & $12.8 \pm 2.1$ & $10.3 \pm 2.2$ \\
6 & $18.2 \pm 1.4$ & $13.5 \pm 1.7^{*}$ & $12.7 \pm 1.9$ & $11.7 \pm 1.9$ \\
7 & $18.3 \pm 1.2$ & $13.1 \pm 1.9$ & $13.1 \pm 1.8$ & $11.6 \pm 2.1$ \\
8 & $17.5 \pm 1.3$ & $16.1 \pm 2.0$ & $10.7 \pm 1.8$ & $9.4 \pm 1.6$ \\
9 & $15.6 \pm 1.3$ & $14.4 \pm 1.9$ & $10.2 \pm 1.6$ & $9.7 \pm 2.1$ \\
10 & $14.4 \pm 1.2^{*}$ & $12.8 \pm 1.8$ & $9.0 \pm 1.4$ & $8.0 \pm 1.2$ \\
\hline
\end{tabular}

* Trial reaching mean criteria of acquisition (15 sec or less)
Table 1

Double-Blind Studies of Acquisition Following Electroshock on the Jump Out Test

\begin{tabular}{ccc}
$\begin{array}{c}\text { PMH Oral Dose } \\
\text { (mg/kg) }\end{array}$ & $\begin{array}{c}10 \text { Acquisition Trials } \\
\text { Mean Latency } \\
\pm \text { S.E. (Sec) }\end{array}$ & $\begin{array}{r}\text { No. of } \\
\text { Rats }\end{array}$ \\
\hline Controls (No. ECS) & $14.6 \pm 0.8$ & 20 \\
Controls (with ECS) & $20.2 \pm 0.6$ & 40 \\
5 & $18.5 \pm 0.9$ & 20 \\
10 & $17.6 \pm 0.8^{*}$ & 20 \\
20 & $15.5 \pm 0.9^{*}$ & 20 \\
40 & $13.7 \pm 0.9^{*}$ & 20 \\
\hline
\end{tabular}

* Significant differences from controls at Duncan's multiple range test $p<0.05$ lone way analysis of variance for all groups: $F$ ration 11:05, $F$ of $.05=2.46)$.

PMH-pretreated animals (Table 2). Thus, control animals only reached acquisition criterion (mean of $15 \mathrm{sec}$ or less) by the ninth trial, whereas PMH-pretreated animals reached acquisition criterion by the third trial at a dose of $40 \mathrm{mg} / \mathrm{kg}$ and by the fourth trial at a dose of $20 \mathrm{mg} / \mathrm{kg}$.

The data clearly show that PMH effectively antagonizes the antegrade amnesic effects of electroconvulsive shock, evidenced by a significant shortening of the mean jump-out time as well as by the number of acquisition trials to criteria. Since the intertrial interval in this study was approximately $10 \mathrm{~min}$ and the total test period was $2 \mathrm{~h}$ after ECS, there is significant indication that PMH enhances consolidation processes of short-term memory. Earlier studies indicated that PMH enhanced consolidation processes when PMH was administered after training (Plotnikoff, 1967; Doty \& Howard, 1968). This enhancement effect of PMH on consolidation of memory processes may be mediated by improved synaptic transmission in the central nervous system (Plotnikoff, 1968).

\section{REFERENCES}

DOTY, B., \& HOWARD, S. Facilitative effects of post-trial magnesium pemoline on avoidance conditioning in relation to problem difficulty. Life Sciences, 1968, 7, 591-597.

PLOTNIKOFF, N. Magnesium pemoline: Enhancement of learning and memory of a conditioned avoidance response. Science, 1966a, 151, 703-704.

PLOTNIKOFF, N. Magnesium pemoline: Enhancement of memory after electroconvulsive shock in rats. Life Sciences, $1966 \mathrm{~b}, 5,1495-1498$.

PLOTNIKOFF, N. Pémoline and magnesium hydroxide: Memory consolidation following acquisition trials. Psychonomic Science, 1967, 9, 141-142.

PLOTNIKOFF, $N$. Learning and memory enhancement by pemoline and magnesium hydroxide (PMH). In J. Wortis (Ed.), Recent advances in biological psychiatry. Vol. X. New York: Plenum Press, 1968. Chap. 9.

SMALL, I. F., SHARPLEY, P., \& SMALL, J. G. Influences of Cylert upon memory changes with ECT. American Journal of Psychiatry, $1968,125,149-152$. 